\title{
Assessing community and region emergency-services capabilities
}

\author{
Z. Shoemaker, L. Eaton, F. Petit, R. Fisher \& M. Collins \\ Infrastructure Assurance Center, Argonne National Laboratory, USA
}

\begin{abstract}
To increase emergency preparedness for communities, steps must be taken to improve both soft (community planning, education and relationships) and hard (core operational capabilities) aspects of preparedness, resilience and recovery. While professional standards and accreditation organizations continue to improve individual capabilities of first responders and preventers, a tool to analyze a community's full complement of prevention, mitigation, response, and recovery capabilities is still lacking. In order to address this area of concern, Argonne National Laboratory has created a methodology to measure a given community or region's capabilities concerning its entire emergency-services sector. The resulting index accounts for emergency medical, law-enforcement, fire-service, search and rescue, explosive-threat response, 911 dispatch, and emergency-management capabilities, in a way that allows communities to analyze their capabilities relative to other communities of comparable size and hazard profile. The methodology captures a community's aid and assistance agreements to measure expansive and redundant capabilities, as well as the presence of governmental coordination of the services, in a systematic manner. This tool can be used to aid communities in assessing their current capabilities as well as laying out a systematic approach to improving community resilience by targeting specific areas of weakness or areas where leveraging outside capabilities may be difficult.

Keywords: emergency services, capabilities index, regional resilience, critical infrastructures.
\end{abstract}




\section{Introduction}

The resilience of a region is a complex concept combining hard (resilience of institutions and infrastructures) and soft (resilience of citizens) aspects [1]. Multiple definitions and methodologies to assess these aspects of regional resilience exist [2-4]. However, all of these definitions and methodologies emphasize the need to characterize the capabilities of a region to anticipate, absorb, adapt to and recover from a potentially disruptive event [5]. The resilience of a given community or region is then seen as the capability of the region to manage (protect against, mitigate, respond to and recover from) an emergency or a disaster.

Of the 18 critical infrastructure and key resources (CIKR) sectors defined in the U.S. National Infrastructure Protection Plan [6], one sector is particularly important to ensuring and ultimately enhancing the Nation's resilience: the emergency-services sector (ESS). As with other CIKR, the resilience of ESS assets directly affects the resilience of a specific region. However, the capabilities of the ESS are also an integral part of the resilience of infrastructures and citizens. The ESS combines the capabilities of all first responders - a key factor in the ability of a region to adapt and react to, as well as recover from, a crisis. As the topic of resilience, its meaning and its importance, is debated, it is vital to identify core functions for resilience management [7]; a high-functioning ESS captures many of those necessary functions.

This paper describes a comprehensive methodology developed to assess ESS capabilities (ESSC), based on their functions, which can be further utilized in characterizing regional resilience. By including the unique response and recovery role of the ESS, researchers can account for the positive impact of a robust ESS on the ability of a region or system to more quickly prevent, respond to and recover from natural or human-caused hazards or, conversely, the negative impact that a low-functioning ESS would have on a jurisdiction. To do so, this paper proposes the use of proxy variables that are closely correlated to an emergency-service subsectorlsegment's ability to perform certain functions.

\section{Emergency-services capabilities}

The main objective in analyzing emergency-services capabilities is to capture the impact of the ESS on the organizations and residents of a given jurisdiction. This tends to be a complex task, as directly measuring variables such as operational functions of first responders and preventers can be difficult and time-consuming. For example, physically assessing the ability of a local fire-protection district to identify and extinguish hot spots at an incident scene might require direct observations of the fire-service professionals over an extended period to witness their performance in identifying and extinguishing blazes. For a short assessment process, repeating such an exercise for multiple variables or functions is not feasible.

Using the above example, a more facile method would be to identify whether the professionals have trained and exercised in identifying and extinguishing hot 
spots, whether they have the equipment necessary to perform the function, and/or whether they have written standard operating procedures for such a task. Although these proxy variables may not always completely define the ability of the fire-service professionals to identify and extinguish hot spots at an incident site, the close correlation of these variables to that ability should still give an accurate depiction of their capabilities. Additionally, measuring a framework that includes planning, training, exercises, procedures, etc., allows researchers to obtain a consistent view of how the organization will function, regardless of the individuals on duty at the time of an incident. Thus, using these proxy variables will allow assessors to conduct the visit more quickly and still reach a valid conclusion.

The ESSC Index (ESSCI) groups nine main "level-1" functions: Emergency Medical Services, Law Enforcement, Fire Services, Search and Rescue, Explosive-Threat Response, Hazardous-Materials Response, Public Safety Answering Point, Emergency Management, and Coordinating Council/Committee. Each of the variables representing the core functions of the ESS captures how specific ESS subsectors/segments operate independently of the others to perform prevention, response and recovery roles, as well as the ability to operate, plan, and exercise together. Each of the nine core functions are characterized by operational capabilities and mutual aid and assistance capabilities. The former analyzes the capabilities of a function to operate on a daily basis in its jurisdiction. This measurement is concerned with potential prevention, response and recovery activities that the function would be able to provide if required. The latter variable (mutual aid and assistance capabilities) analyzes the ability of the function, through documented preexisting agreements, to either supplement its capabilities if they are overwhelmed or lost or to expand its capabilities by having agreements in place for specialized staff or equipment. Combining these two variables gives an overall picture of the resources available to a jurisdiction should a potential incident occur.

Each of the nine functions, except the Coordinating Council/Committee variable, is made up of two level-2 elements: Operational Capabilities and Mutual Aid/Assistance Capabilities. The Coordinating Council/Committee variable does not analyze assistance capabilities, but simply the function of the council or committee. Operational Capabilities group, for each function, five main level-3 capabilities (Facilities/Equipment, Staffing, Training/Exercises, Planning, and Communication) as well as other specific capabilities (e.g., Identification of Hazards, Mitigation Programs, Incident Management, and Resource Management for Emergency Management). These capabilities, defined by sector representatives and subject-matter experts based on various standards in the field [8-10], combine various level-4 characteristics of the ESS.

The ESSCs are thus structured into four levels of information (Functions, Elements, Capabilities and Characteristics) under a tree organization which is based on the multiattribute utility theory (MAUT) [11]. This tree organization of all information characterizing the capabilities of the ESS enables one to obtain an overall index that will allow comparison of the capabilities of different jurisdictions. Indeed, all collected information can be aggregated to calculate an 
index that represents the capabilities of the ESS to respond to a specific event. The next section explains the methodology used to do so, using as an illustrative example the roll-up of an assessment from the Identification of Hazards characteristic of Emergency Management to the overall index value (ESSCI).

\section{Index methodology}

Argonne National Laboratory developed a methodology in three steps for the determination of an index that allows for the calculation and comparison of jurisdiction and community prevention, response, and recovery capabilities:

- Collection of data;

- Calculation of ESSCs based on the data collected; and

- Visualization of the capabilities of a jurisdiction and comparison to other like jurisdictions.

\subsection{Data collection}

The data collection is achieved through a questionnaire that captures the main information (around 375 questions combining over 1800 variables) characterizing emergency-services capabilities in a given jurisdiction. The questionnaire has been developed in collaboration with subject-matter experts to ensure it captures accurate and transparent information that can be compared and interpreted in a consistent manner. The questionnaire was built to be completed by individuals in charge of the various emergency-service functions within a community, and to be done in a limited amount of time. The survey covers the nine core functions of the ESS to prevent, respond to, and recover from a possible incident.

\subsection{Calculation of the emergency-services sector capability index}

Each question (raw data), and all components and subcomponents of the ESSCI, is assigned a weight representing its importance relative to other questions/components/subcomponents in its grouping. The weights were obtained in accordance with the principles of "decision analysis," an approach that helps manage risk under conditions of uncertainty [12, 13]. The methodology is based on creating a numerical representation of the value pattern by comparing different elements of a jurisdiction and by using relations "better than" and "equal in value to" to define their relative importance. Another important element in this decision analysis tool is the transitivity of the ranking, which means that if an element $\mathrm{A}$ is more important than an element $\mathrm{B}$, and $\mathrm{B}$ is more important than an element $\mathrm{C}$, then logically A will be more important than C. This approach produces a relational representation of capability alternatives by providing a numerical value assignment for each of its components.

The weights for a set of components depend on the ranges (worst to best) that are included as options in the question set. Preferences for the specific values 
within the ranges of single components have been provided by subject-matter experts via an elicitation process.

The individual variables are arranged such that they can be aggregated up from the raw-data (level-5) stage into broader variables, culminating through the additive process into an overall ESSCI value. This value is obtained by using a sum of all the weighted components that characterize the capabilities of the ESS.

Table 1 portrays an example for the determination of the Hazard Consequence Analysis Index. For level 4, the weights are divided by the sum of all the weights to determine the individual weight of each component. The optimal plan is one that integrates all of the components and should correspond to an index value of 100 .

The emergency-management program in the example has a hazard identification plan that considers the consequences of identified hazards on people, first responders, continuity of operations, and infrastructure. The only element not considered is the consequences on the economy. At the raw-data level, a program is awarded an answer value of 100 for an affirmative answer and a 0 for a negative one. Combining the weighted values of the elements through a summation equation gives a hazard consequence analysis index value of 82.10 (Table 1).

Table 1: $\quad$ Level-4 Hazard consequence analysis index (illustrative example).

\begin{tabular}{|c|c|c|c|}
\hline $\begin{array}{c}\text { Hazard Consequence Analysis } \\
\text { Component }\end{array}$ & Weight & Answer & $\begin{array}{c}\text { Weighted } \\
\text { Index }\end{array}$ \\
\hline $\begin{array}{c}\text { The plan documents consideration of } \\
\text { people. }\end{array}$ & 0.218 & Yes $^{\mathrm{a}}$ & 21.80 \\
\hline $\begin{array}{c}\text { The plan documents consideration of } \\
\text { first responders. }\end{array}$ & 0.218 & Yes & 21.80 \\
\hline $\begin{array}{c}\text { The plan documents consideration of } \\
\text { continuity of operations. }\end{array}$ & 0.190 & Yes & 19.00 \\
\hline $\begin{array}{c}\text { The plan documents consideration of } \\
\text { infrastructures. }\end{array}$ & 0.195 & Yes & 19.50 \\
\hline $\begin{array}{c}\text { The plan documents consideration of } \\
\text { economy. }\end{array}$ & 0.179 & $\mathrm{No}^{\mathrm{b}}$ & 0.0 \\
\hline \multicolumn{2}{|c|}{ Level-4 Hazard Consequence Analysis Index } & 82.10 \\
\hline
\end{tabular}

${ }^{\mathrm{a}}$ Yes corresponds to a numerical value of $100 .{ }^{\mathrm{b}}$ No corresponds to a numerical value of 0 .

Level-4 characteristics are aggregated into level-3 capabilities, which represent the core capabilities of each ESS function, such as the equipment or staffing or an operational variable such as the identification of hazards for an emergency management program. For example, the hazard consequence analysis variable, level 4, is one of three components of the level-3 Identification of Hazards capability (Table 2).

The hazard identification plan is considered the most important component for the identification of hazards, with a weight of 0.360 . The relative importance (weight) of the Hazard Consequence Analysis is 0.310 . By multiplying the value 
of the Hazard Consequence Analysis Index (82.10) by its weight, we obtain a weighted Hazard Consequence Analysis value of 25.45. This value is added to the other weighted components that constitute identification of hazards (level 4) to obtain an Identification of Hazards Capability Index of 55.36 (Table 2).

Table 2: Level-3 identification of hazards capability index (illustrative example).

\begin{tabular}{|c|c|c|c|}
\hline $\begin{array}{l}\text { Identification of Hazards Component } \\
\text { (Level 4) }\end{array}$ & $\begin{array}{l}\text { Level-4 } \\
\text { Weight }\end{array}$ & $\begin{array}{c}\text { Level-4 } \\
\text { Index }\end{array}$ & $\begin{array}{l}\text { Weighted } \\
\text { Index }\end{array}$ \\
\hline Hazard Identification Plan & 0.360 & 50.00 & 18.00 \\
\hline Hazard Risk Assessment & 0.330 & 36.10 & 11.91 \\
\hline Hazard Consequence Analysis & 0.310 & 82.10 & 25.45 \\
\hline \multicolumn{3}{|c|}{ Level-3 Identification of Hazards Capability Index } & 55.36 \\
\hline
\end{tabular}

Level-3 capabilities are aggregated to define level-2 elements. This level represents the two main elements that characterize function (Operational Capabilities and Mutual Aid/Assistance Capabilities). Identification of Hazards is one of the eleven level-3 variables that are aggregated to characterize the operational-capabilities element of emergency management (Table 3).

For Emergency Management, operational capability weights vary from 0.0794 to 0.1148 . In the example, the community has a full-time, dedicated Emergency Operations Center with a backup that can handle full-scale operations. However, there is no Joint Information Center (index $=70.18$ ). There is a full-time employee exclusively in charge of emergency management, but supporting members lack specialized training (index $=76.47$ ). All members with emergency-management functions are trained on the emergency-operations plan, but training on other key plans and procedures is missing. Local and regional exercises have been previously conducted with program stakeholders (index $=$ 25.13). The emergency-management program has a comprehensive set of plans; however, these plans do not address financial procedures for recovery (index $=$ 91.68). Mitigation programs include all hazards reasonably mitigated from the hazard identification plan, including goals for risk reduction (index $=86.56$ ). The incident management system lacks several elements, but includes unified command with multiagency coordination (index $=32.88$ ). The community has a resource-management plan but has not conducted a gap analysis (index $=34.55$ ). The community can use different telecommunication methodologies and warning systems (index $=86.56$ ); however, there is no documented plan for public information dissemination or collection (index $=0.00$ ).

The relative importance (weight) of the Identification of Hazards capability is 0.1059. By multiplying the value of the Identification of Hazards Index (55.36) by its weight, we obtain a weighted Identification of Hazards Index of 5.36. This new value is added to the other weighted index values that constitute Emergency Management (level 3) to obtain a level-2 Emergency-Management Operational Capabilities Index of 58.02 (Table 3). 
Table 3: Level-2 emergency-management operational capabilities index (illustrative example).

\begin{tabular}{|c|c|c|c|}
\hline $\begin{array}{c}\text { Operational Capabilities Component } \\
\text { (Level 3) }\end{array}$ & $\begin{array}{c}\text { Level-3 } \\
\text { Weight }\end{array}$ & $\begin{array}{c}\text { Level-3 } \\
\text { Index }\end{array}$ & $\begin{array}{c}\text { Weighted } \\
\text { Index }\end{array}$ \\
\hline Facilities Equipment & 0.1118 & 70.18 & 7.85 \\
\hline Staffing & 0.1148 & 76.47 & 8.78 \\
\hline Training/Exercises & 0.1088 & 25.13 & 2.73 \\
\hline Planning & 0.1088 & 91.68 & 9.97 \\
\hline Identification of Hazards & 0.1059 & 55.36 & 5.86 \\
\hline Mitigation Programs & 0.0882 & 86.56 & 7.63 \\
\hline Incident Management & 0.0912 & 32.88 & 3.00 \\
\hline Resource Management & 0.0882 & 34.55 & 3.05 \\
\hline Organizational Communication & 0.1029 & 88.93 & 9.15 \\
\hline Crisis Communication/Public & 0.0794 & 0.00 & 0.00 \\
\hline Information & \multicolumn{3}{|c|}{} \\
\hline Level-2 Emergency-Management Operational Capabilities Index & 58.02 \\
\hline
\end{tabular}

Table 4: Level-1 emergency-management index (illustrative example).

\begin{tabular}{|c|c|c|c|}
\hline $\begin{array}{c}\text { Coordination Component } \\
\text { (Level 2) }\end{array}$ & $\begin{array}{c}\text { Level-2 } \\
\text { Weight }\end{array}$ & $\begin{array}{c}\text { Level-2 } \\
\text { Index }\end{array}$ & $\begin{array}{c}\text { Weighted } \\
\text { Index }\end{array}$ \\
\hline Operational Capabilities & 0.752 & 58.02 & 43.63 \\
\hline $\begin{array}{c}\text { Mutual Aid/Assistance } \\
\text { Capabilities }\end{array}$ & 0.248 & 68.52 & 16.99 \\
\hline \multicolumn{2}{|c|}{ Level-1 Emergency-Management Index } & 60.62 \\
\hline
\end{tabular}

Level-2 elements are aggregated to define level-1 functions, which represent the major sections of an ESS (Table 4).

Operational Capabilities is considered the most important element for emergency management, with a weight of 0.752. The Mutual Aid/Assistance Agreements element is considered approximately a third as important as the Operational Capabilities element. This would mean that a jurisdiction with the optimal combination of operational capabilities but without any preexisting mutual aid/assistance agreements could achieve a maximum emergencymanagement index value of 75.20. Conversely, a community with no operational capabilities but a full range of mutual aid/assistance agreements that were taken into account during jurisdictional planning and regularly exercised could achieve a maximum emergency-management index value of 24.80 .

The relative importance (weight) of operational capabilities is 0.752 . By multiplying the value of the emergency-management operational capabilities index (58.02) by its weight, we obtain a weighted index of 43.63. This value is 
added to the weighted mutual aid/assistance element (level 2) to obtain an overall emergency-management index of 60.62 (Table 4).

Finally, the overall ESSCI (Table 5) is obtained by aggregating nine level-1 functions: Emergency Medical Services, Law Enforcement, Fire Services, Search and Rescue, Explosive-Threat Response, Hazardous-Materials Response, Public Safety Answering Point, Emergency Management, and the Sector Coordinating Council/Committee. Emergency Medical Services, Law Enforcement and Fire Services were selected as the most important of the nine functions, each receiving a weight of 0.1493 . The next most important function is the Public Safety Answering Point, which has a weight of 0.1342 , followed by Emergency Management at 0.1269 . The remaining five functions have weights that range from 0.0969 for Hazardous Materials Response to 0.0448 for the Coordinating Council/Committee variable.

Table 5: $\quad$ Emergency-services sector capability index (illustrative example).

\begin{tabular}{|c|c|c|c|}
\hline ESS Function (Level 1) & $\begin{array}{c}\text { Level-1 } \\
\text { Weight }\end{array}$ & $\begin{array}{c}\text { Level-1 } \\
\text { Index }\end{array}$ & $\begin{array}{c}\text { Weighted } \\
\text { Index }\end{array}$ \\
\hline Emergency Medical Services & 0.1493 & 51.08 & 7.63 \\
\hline Law Enforcement & 0.1493 & 67.45 & 10.07 \\
\hline Fire Services & 0.1493 & 69.21 & 10.33 \\
\hline Search and Rescue & 0.0672 & 47.43 & 3.19 \\
\hline Explosive Threat Response & 0.0821 & 0.00 & 0.00 \\
\hline $\begin{array}{c}\text { Hazardous Materials } \\
\text { Response }\end{array}$ & 0.0969 & 16.89 & 1.64 \\
\hline $\begin{array}{c}\text { Public Safety Answering } \\
\text { Point }\end{array}$ & 0.1342 & 74.75 & 10.03 \\
\hline Emergency Management & 0.1269 & 60.62 & 7.69 \\
\hline $\begin{array}{c}\text { Coordinating } \\
\text { Council/Committee }\end{array}$ & 0.0448 & 26.52 & 1.19 \\
\hline Overall Emergency-Services Sector Capability Index & 51.77 \\
\hline \multicolumn{2}{|l|}{} \\
\hline
\end{tabular}

The jurisdiction characterized in this example has fairly robust LawEnforcement, Fire-Services, Public Safety Answering Point, and EmergencyManagement functions. The jurisdiction only has the services of a hazardousmaterials response team through mutual aid/assistance agreements and does not have an explosive-threat response team in the jurisdiction, nor does it have preexisting agreements to identify who would provide those services if needed.

By multiplying the value of the emergency-management index by its weight (0.1269), we obtain a weighted emergency-management index of 7.69. This value is added to the other weighted index values of emergency-services functions to obtain an overall ESSCI of 51.77 (Table 5).

This method of characterizing the capabilities of the ESS of a jurisdiction allows for consideration of the impact of emergency services on the individuals 
within the supported community and CIKR resilience within its region, as well as how capabilities vary within the sector as a whole. A score of 100 on the ESSCI is not necessarily the expected level of capability for emergency-services programs. Rather, a score of 100 would represent an optimal program that would rarely be observed. An expected level of capability would come not from a prefixed number on the index, but rather, from an analysis of the average capability score, combined with examination of minimally acceptable capabilities from within each of the Level-1 and -2 variables.

The information required to complete the ESSCI is collected during an on-site assessment visit; however, a self-assessed ESSCI score could also be derived if deemed appropriate. In this case, the data would be obtained from a survey that corresponds to the variables in the index and that could be modified to reflect future changes. This index, based on a jurisdiction's capabilities in terms of emergency services, is also useful to integrate into separate programs that characterize vulnerability and resilience of a region or system.

\subsection{Visualization of the capabilities of a jurisdiction}

Although an individual ESSCI value is important with regard to the data it represents, it can be difficult to fully interpret without context. Without a frame of reference, the ESSCI's value does not convey its full meaning. For instance, when there is no understanding of the other scores, does an overall ESSCI score of 51.77 lead one to believe that a jurisdiction is well prepared to prevent or respond to an emergency? Indeed, the value of an ESSCI is strongly related to the jurisdiction and its environment. A comparative framework is thus necessary. Using an ESSCI value to compare similar jurisdictions with respect to regional resilience can provide additional vital benefits.

To facilitate comparisons between different possible actions, Argonne has developed a Web-based tool, the ESS Dashboard. This tool allows city or county officials, simply by selecting possible options to consider and changing characteristics at each level, to immediately see the benefits of potential changes to the overall values of the calculated indices.

The Dashboard provides various interactive windows that are particularly relevant to supporting decisions for proactive disaster prevention and management. Figure 1 shows an example of these windows for the communication capability of the Fire-Services function. It shows the different possible options for consideration for communication; three counters give the values for the overall index as well as for the selected function (Fire Services) and element (Operational Capabilities). The Dashboard gives users the ability to change parameters, speedily see results, and assess different scenarios, making it a very powerful tool that is particularly relevant with regard to strategic planning and budgeting.

Combining multiple jurisdiction ESSCI values into a region-specific dashboard adds a new level of information. Region-specific ESSCIs demonstrate the potential effects of prioritizing measures for a particular jurisdiction beyond its own immediate benefits. The list of common options, identified through 
comparisons with those of other jurisdictions, can help city or county officials make decisions regarding a region-specific resilience and prepardness strategy.

The ESSCI can be used to aid communities in assessing their current capabilities as well as laying out a systematic approach to improving capabilities by targeting specific areas of weakness or areas where leveraging outside capabilities may be difficult. It can be combined with other elements to characterize the resilience of a region.

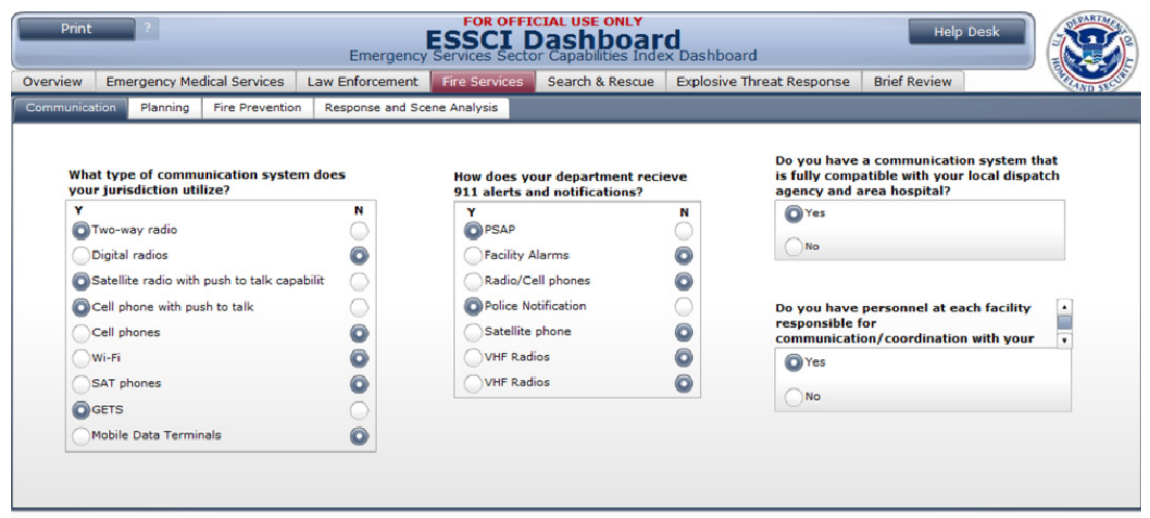

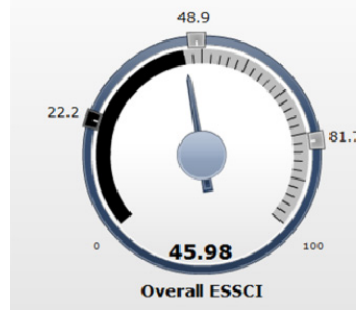

Figure 1: The ESSCI dashboard screen.

\section{Applicability of the ESSCI to assessing regional resilience}

Community resilience or regional resilience can be defined as the capability of a geographic location, its inhabitants and organizations to anticipate risk, limit impact, and bounce back rapidly through survival, adaptability, evolution, and growth in the face of turbulent change [14]. Regional resilience is thus related to the capabilities of a jurisdiction to resist, adapt to, and recover from a disruptive event. To fully measure regional resilience, all component parts (e.g. people, institutions and organizations) must be taken into account. In order to do so, the topic is often separated into two main aspects to be analyzed: soft and hard [1]. Soft aspects include the capacities of individuals and institutions to adopt and maintain a planning mindset, develop physical and psychological toughness, be self-sufficient, respond appropriately in the face of a disaster, and learn and adapt [1]. Hard aspects include the capacities of governments, organizations and 
systems to maintain structures and services (i.e., CIKR), recover quickly, shift from degraded to alternative resources, and learn and adapt [1]. The ESS serves a critical role in soft aspects of regional resilience as it constitutes the community's first line of defense and helps frame a community mindset, while it also plays an integral role in hard aspects through hazard prevention and reduction of consequences from natural and human-caused hazards [15]. Thus, while the characterization of the ESS is only one of the elements that need to be considered in order to analyze the overall resilience of a geographic area, capturing the capabilities of the ESS is vital as it promotes both hard and soft aspects of regional resilience. The ESS is a critical infrastructure sector that needs to be itself resilient to both natural and man-made hazards as well as serve as a tool to promote resilience of other infrastructures and facilities.

Beyond its own benefits, the ESSCI also complements other indices that have been developed by Argonne National Laboratory to assess the protection, vulnerability, resilience, and criticality of facilities combined with information about the susceptibility of assets to specific threat types $[2,16]$. By combining these indices with other programs utilized by DHS along with other tools to more specifically assess the soft aspects of regional resilience, it is possible to form a more thorough representation of specific area resilience and of risk in general.

\section{Conclusion}

In a complex and interconnected world, it is vital to enhance the preparedness and resilience of society. The ESS is uniquely important as it constitutes a core function in the resilience of all CIKR sectors as well as the population in general; therefore, it is essential to consider its vulnerability, resilience, criticality, and capabilities if we are to accurately assess the risk and resilience of a geographic area. The proposed ESSCI, based on accepted programmatic elements, allows for consideration of the particular capabilities of the ESS in a global methodology.

\section{References}

[1] Resilience - Concept Development: an Operational Framework for Resilience, Science and Technology Directorate, U.S. Department of Homeland Security: Washington, D.C., 2009.

[2] Constructing a Resilience Index for the Enhanced Critical Infrastructure Protection Program, ANL/DIS-10-9, Decision and Information Sciences Division, Argonne National Laboratory: Argonne, Illinois, 2010.

[3] Community \& Regional Resilience Institute, Oak Ridge National Laboratory: Oak Ridge, Tennessee, 2010, available at http://www.resilientus.org/ (accessed December 15, 2010).

[4] Resilient Organizations, New Zealand, 2010, available at http://www.resorgs.org.nz/index.shtml (accessed December 15, 2010).

[5] National Infrastructure Advisory Council, Critical Infrastructure Resilience, Final Report and Recommendations, U.S. Department of Homeland Security: Washington, D.C., 2009. 
[6] National Infrastructure Protection Plan: Partnering to Enhance Protection and Resiliency, U.S. Department of Homeland Security: Washington, D.C., 2009, available at http://www.dhs.gov/xlibrary/assets/NIPP Plan.pdf (accessed December 15, 2010).

[7] White Paper: The Infrastructure Security Partnership, Infrastructure Resilience, and Interdependencies, The Infrastructure Security Partnership: Alexandria, Virginia, 2010.

[8] EMAP Standard, Emergency Management Accreditation Program, 2007, available at http://www.emaponline.org (accessed December 15, 2010).

[9] NFPA1710 Standard for the Organization and Deployment of Fire Suppression Operations, Emergency Medical Operations, and Special Operations to the Public by Career Fire Departments, National Fire Protection Association: Boston, Massachusetts, 2010.

[10] NIMS Resource Center, Federal Emergency Management Agency, U.S. Department of Homeland Security: Washington, D.C., 2010, available at http://www.fema.gov/emergency/nims/ (accessed December 15, 2010).

[11] Dyers, J., MAUT - Multiattribute Utility Theory. International Series in Operations Research \& Management Science, 1, Volume 78, Multiple Criteria Decision Analysis: State of the Art Surveys, IV, pp. 265-292 (2005).

[12] Keeney, R.L., Value-Focused Thinking: A Path to Creative Decisionmaking, Harvard University Press: Cambridge, Massachusetts, 1992.

[13] Keeney, R.L. \& Raiffa, H., Decisions with Multiple Objectives: Preferences and Value Tradeoffs, John Wiley and Sons: New York, 1976.

[14] Plodinec, J., Definitions of resilience: an analysis, Community \& Regional Resilience Institute: Oak Ridge, Tennessee2009, available at http://www.resilientus.org/library/CARRI_Definitions_Dec_2009 1262802 355.pdf (accessed December 15, 2010).

[15] Emergency Services Sector: Critical infrastructure and key resources, U.S. Department of Homeland Security: Washington, D.C., 2010, available at http://www.dhs.gov/files/programs/gc 1189094187811.shtm (accessed December 15, 2010).

[16] Constructing Vulnerability and Protective Measures Indices for the Enhanced Critical Infrastructure Protection Program, ANL/DIS-09-4, Decision and Information Sciences Division, Argonne National Laboratory: Argonne, Illinois, 2009. 